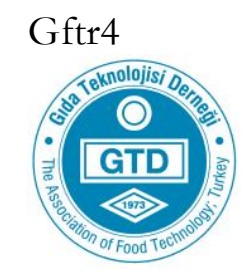

\title{
GIDA
}

THE JOURNAL OF FOOD

E-ISSN 1309-6273, ISSN 1300-3070

Araştırma / Research

GIDA (2020) 45(5) 872-880

doi: $10.15237 /$ gida.GD20076

\section{BEYAZ PEYNİRDEN İZOLE EDİLEN CRYPTOCOCCUS HUMICOLA SUŞLARININ STARTER AKTIVITTELERINIIN ARAŞTIRILMASI}

\author{
Dilek Uzundağ ${ }^{1, *}$, Selda Arslan ${ }^{1}$, Zehranur Yüksekdağ ${ }^{1}$, \\ Yavuz Beyatiı ${ }^{1}$, Abdulla Sakalli ${ }^{2}$ \\ ${ }^{1}$ Gazi Üniversitesi, Fen Fakültesi, Biyoloji Bölümü, Biyoteknoloji AbD, Ankara, Türkiye \\ 2 İskenderun Teknik Üniversitesi, Endüstri Mühendisliği Bölümü, İskenderun, Hatay, Türkiye
}

Geliş / Received: 04.06.2020; Kabul / Accepted: 09.08.2020; Online bask1 / Published online: 15.08.2020

Uzundağ, D., Arslan, A., Yüksekdağ, Z., Beyatlı, Y., Sakallı, A. (2020). Beyaz peynirden izole edilen Cryptococcus bumicola suşlarının starter aktivitelerinin araştırlması. GIDA (2020) 45(5) 872-880 doi: 10.15237 /gida.GD20076

Uzundağ, D., Arslan, A., Yüksekdă, Z., Beyatl, Y., Sakall, A. (2020). Investigation of starter activity of the yeast species Cryptococcus humicola isolated from white cheese. GID A (2020) 45(5) 872-880 doi:10.15237/gida.GD20076

\section{ÖZ}

Starter kültür, kontrollü koşullarda standart kültür elde etmek için endüstride kullanılan mikroorganizmalardır. Mayalar destekleyici kültürler olarak fermente ürünlerin olgunlaşmasında, aroma ve kıvamın gelişmesinde katkıda bulunmaktadırlar. Cryptococcus bumicola suşlanı birçok peynir çeşidinde doğal olarak bulunmaktadır. Bu mayanın gıda endüstrisinde kullanılabilmesi için starter özelliklerinin belirlenmesi oldukça önemlidir. Bu çalışmada peynirden izole edilen 8 Cyrptococcus bumicola maya izolatlarının bazı starter kültür özelliklerinin belirlenmesi amaçlanmıştır. Maya izolatlarının proteolitik ve lipolitik aktiviteleri, maya içeren steril disklerin etrafinda oluşan şeffaf zonlara göre tayin edilmiştir. Mayaların proteolitik aktiviteleri sonucu oluşturdukları şeffaf zon çaplarının büyüklükleri 10.23-17.40 mm arasında ölçülürken, lipolitik aktiviteleri sonucu oluşan zon çapları ise 9.12-12.44 mm arasında değişmiştir. 8 maya izolatından 2 izolat (C. bumicola MBP2 ve MBP3) üreyi hidroliz edemezken, 1 izolat (C. humicola MBP7) üreyi güçlü hidroliz etmiştir. Farklı tuz konsantrasyonlarında maya izolatlannın (MBP4 ve MBP6 izolatlanı hariç) en yüksek canlilığn \%4 $\mathrm{NaCl}$ konsantrasyonunun olduğu tespit edilmiştir. Ayrıca, C. bumicola MBP4 ve MBP6 izolatları hariç diğer izolatların $37^{\circ} \mathrm{C}$ 'de daha yüksek canlllık değerlerine sahip olduğu belirlenmiştir. Mayaların amilaz enzim aktivitelerinin 8.87-14.54 $\mathrm{mm}$ arasında değişmektedir.

Anahtar kelimeler: Maya, starter aktivite, proteolitik aktivite, lipolitik aktivite, Cryptococcus bumicola.

\section{INVESTIGATION OF STARTER ACTIVITY OF THE YEAST SPECIES CRYPTOCOCCUS HUMICOLA ISOLATED FROM WHITE CHEESE}

\section{ABSTRACT}

Starter culture are microorganisms used in industry to achieve standard culture under controlled conditions. Yeasts as supportive cultures contribute to the development of ripening, aroma and

\footnotetext{
* Yazışmalardan sorumlu yazar /Corresponding author

$\triangle$ dilekuzundag@gmail.com

(6) (+90) 5078814885
}

Dilek Uzundağ; ORCID no: 0000-0002-6256-574X

Selda Arslan; ORCID no: 0000-0002-1711-8991

Zehranur Yüksekdağ; ORCID no: 0000-0002-0381-5876

Yavuz Beyatlı; ORCID no: 0000-0002-0458-4475

Abdulla Sakallı; ORCID no: 0000-0002-2488-7318 
consistency of fermented products. Cryptococcus bumicola strains are naturally found in many cheese varieties. To use this yeast in the food industry, it is very important to determine the starter properties. In this study, it was aimed to determine some starter culture properties of 8 Cyrptococcus humicola yeast isolates isolated from cheese. Proteolytic and lipolytic activities of these isolates were determined according to clear zones around the sterile discs. The diameters of clear zones of the yeasts were measured in the range of $10.23 \mathrm{~mm}$ to $17.40 \mathrm{~mm}$ at proteolytic activity whereas zone diameters were measured in the range between $9.12 \mathrm{~mm}$ and $12.44 \mathrm{~mm}$ at lipolytic activity. While two isolates $(C$. bumicola MBP2 and MBP3) from eight yeast isolates could not hydrolyze urea, one isolate (C. bumicola MBP7) effectively hydrolyzed urea. At different salt concentrations, yeast isolates (except MBP4 and MBP6 isolates) were found to have the highest viability at $4 \% \mathrm{NaCl}$ concentration. Except for $C$. bumicola MBP4 and C. bumicola MBP6 isolates, other isolates had higher viability values at $37^{\circ} \mathrm{C}$. The amylase enzyme activity zone diameters of the yeasts were measured between 8.87-14.54 mm.

Keywords: Yeast, starter activity, proteolytic activity, lipolytic activity, Cryptococcus humicola.

\section{GİRİ̧̧}

Beslenme alışkanlıklarımızda süt ve süt ürünleri önemli bir yer tutmaktadır. Dünyada süt ürünleri içinde en fazla tüketilen süt ürünü ise peynirdir (Eroğlu ve Özcan, 2018). Peynir içerdiği yüksek biyolojik değerli proteinler, vitaminler ve mineraller bakımından besin değeri bakımından oldukça zengindir. Dünyada ve ülkemizde hem peynir üretimi hem de peynir tüketimi gün geçtikçe artmaktadır (Kara ve Akkaya, 2015).

Starter kültürler çeşitli süt ürünlerinin üretiminde lezzet, yapı, tekstür ve görünüm bakımından arzu edilen nitelikleri kazandırmak amacıyla, süte katılan seçilmiş mikroorganizmaların kültürleri olarak tanımlanırlar. Endüstriyel boyutta Beyaz peynir üretiminde ise pastörize inek, koyun ve keçi sütleri kullanılır. Süte uygulanan pastörizasyon işlemleri, patojen ve zararlı mikroorganizmaların yanında mevcudiyeti arzu edilen ve starter kültür olarak bilinen mikroorganizmaların çoğunun da tahrip olmasına neden olur. $\mathrm{Bu}$ nedenle uygulanan isı işlemleri sonrasi arzu edilen tat ve aroma da peynir elde edebilmek için belirli mikroorganizmaların saf veya karışık kültürlerinin kullanımı teknolojik bir zorunluluk haline gelir (Tekinşen, 2000; Oğuz ve Andiç, 2020). Ancak ülkemizde endüstriyel boyutta starter kültür üretiminin olmaması, peynir üreticilerinin dışa bağımlı hale getirmiştir bu da ülkemizdeki starter kültür çalışmalarına olan ilgiyi artırmaktadır (Soran ve Çelik, 2018).

Peynir çeşitlerine özgü aromayı, tadı ve yapısal özellikleri belirleyen ise peynir mikrobiyotasındaki mikroorganizmalardır. Peynir üretiminden peynirin olgunlaşmasına kadar geçen sürede kullanılan mikroorganizmalar birincil starter kültürler ve ikincil starter kültürleri olarak gruplandırilirlar. Birincil starter kültürler arasında çoğunlukla laktik asit bakterileri yer alır ve bu bakteriler laktozdan laktik asit üretimi ile peynirin karakteristik tadı için gerekli bir takım biyokimyasal olaylardan sorumludurlar (Irlinger vd., 2017). İkincil starter kültürler ise mayalar, küfler, propiyonik asit bakterileri, korineformlar, stafilokoklar ve starter olmayan laktik asit bakterileridir (Gürsoy ve Türkmen, 2018). Oldukça heterojen olan bu grup peynirin olgunlaşma sürecinde aktif rol oynamaktadır (Picon, 2018). Peynirin olgunlaşma aşamasında ikincil starter kültürlerin aktiviteleri, peynirin olgunlaşma süresini, endüstriyel boyutta üretilen peynirin tipini ve en önemlisi oluşan peynirin lezzetini etkilemektedir (Cotter ve Beresford, 2017; Lee vd., 2018; Oğuz ve Andiç, 2020).

Peynir tipi ile yakın ilişkili olan mayalar, peynirlerin sert veya yarı sert olmast için kullanılır. Mayalar kalıplardan çıkarılan taze peynirlerin üzerine çözelti halinde püskürtülerek ya da istenilen peynir tipine göre kazanlarda çiğ süte değişen oranlarda eklenir (De Vuyst vd., 2016; Karaman vd., 2018). Tüm bunlara ilaveten mayaların değişik tipteki peynirlerin mikrobiyotasında önemli bir yere sahip olması destek kültür olarak kullanılabilmeleri açısından dikkat çekicidir (Suzzi vd., 2001).

Mayaların olgunlaşma süresince başlıca katkısı ise özellikle ortam pH'ını düşüren laktik asidi kullanarak bakteriyel gelişmeyi desteklemek ve 
olgunlaşmanın ikinci kademesini başlatmaktır. Mayaların olgunlaşma süresince peynir pH'sında meydana getirdiği bu değişiklik sadece laktik asit kullanımı ile ilgili olmayıp, proteolizden kaynaklanan alkali metabolizma ürünleri de $\mathrm{pH}$ 'y1 düşürebilmektedir (Suzzi vd., 2001; Rossouw vd., 2016). Bunun yanında mayaların peynir lezzet ve aromasına katkıları, bazı türlerin genellikle laktozu fermente etme ve bunun sonucu olarak etanol, asetaldehit, etil asetat ve etil butirat oluşturmalarına bağlanabilir. Bazı mayaların yüksek lipolitik ve proteolitik aktiviteye sahip olmalarn, aminoasit, yağ asitleri ve esterler gibi aroma oluşumuna öncülük eden maddelerin meydana gelmesinde büyük rol oynamaktadır. Bununla birlikte mayalar, diğer mikroorganizmalar için gerekli B vitaminleri; pantotenik asit, niasin, riboflavin ve biotin gibi bazı gelişme faktörlerini salgılayarak gelişimi desteklemektedir (Ferreira ve Viljoen, 2003).

Mayaların enzimatik özellikleri, genellikle proteinaz ve peptidazlarin aktiviteleri sonucu meydana gelen acı peptitlerin parçalanmasında da önemli rol oynamaktadır. Esas itibariyle, ac1 peptitlerin daha küçük moleküllü peptitlere ve aminoasitlere parçalanmasında mayaların aminopeptidazları ve karboksipeptidazları katkıda bulunmaktadır (Wyder, 2001). Kisaca mayalanın peynir üretiminde doğal veya kontrollü destek kültür olarak kullanımı ile ilgili özellikler; laktoz fermantasyonu, aroma bileşenleri oluşumu, laktat asimilasyonu, birincil starter ile olumlu interaksiyonu, proteolitik ve lipolitik özellikler olarak özetlenebilir (Fröhlich-Wyder vd., 2019).

Starter kültür olarak en büyük ve kiymetli grubu oluşturan mikroorganizmalar arasında laktik asit bakterileri (LAB) kullanılmaktadır. Gıda kaynaklı çoğu LAB, GRAS (Genel Olarak Güvenilir) statüsünde olmasına rağmen, LAB arasında fazlalaşan antibiyotik dirençlilik ve bu dirençliliğin patojen bakterilere aktarılabiliyor olmas1, LAB'ın özellikle 1sıl işlem yapılmadan tüketilen gıdalarda starter kültür olarak kullanılmasını sınırlamaktadır (Ksonzeková vd., 2016). Bu nedenle peynirlerden izole edilen mayaların starter kültür olarak değerlendirilmeleri üzerinde araştırmalar gün geçtikçe artmaktadır.
$\mathrm{Bu}$ amaçla bu çalsşmada, beyaz peynirden izole edilen 8 Cryptococcus bumicola maya izolatının proteolitik aktivite, lipolitik aktivite, üreyi hidroliz etme yeteneği, farklı tuz konsantrasyonlarında ve s1caklık derecelerinde canlilık miktarları ve amilaz enzim aktivitesi gibi bazı starter kültür özelliklerinin belirlenmesi amaçlanmışur.

\section{MATERYAL VE YÖNTEM \\ Çalışmada Kullanılan Mayalar}

Bu çalışmada, Gazi Üniversitesi Fen Fakültesi Biyoloji Bölümü Biyoteknoloji Laboratuvarr'nda daha önce yürütülmüş, Abudureyimu MAIHEBUBAI'ın Doktora Tezi kapsaminda kullanılmıs olan Beyaz peynirden izole edilen ve API 32C (bioMerieux) sistemi ile biyokimyasal tanıları yapılmış 8 maya izolatı kullanılmışır.

\section{Mayaların Proteolitik, Lipolitik ve Amilaz Enzim Aktivitelerinin Belirlenmesi}

Mayaların proteolitik, lipolitik (Piotr vd., 2005) ve amilaz enzim aktivitelerinin belirlenmesinde (Kim vd., 2004) spot agar yönetimi kullanılmıştır. Mayalar YPD (Yeast Extract-Peptone-Dextrose) s1v1 besiyerinde $37^{\circ} \mathrm{C}$ de 48 saatte aktifleştirilmiştir. Aktif kültürlerin optik yoğunlukları spektrofotometre de (Hithachi, Japonya) 600 nm'de 0.6'ya ayarlanmıştır. Proteolitik aktivitenin belirlenmesinde Skim milk agar (SMA) (3 g beef ekstrakt, $5 \mathrm{~g}$ pepton, $10 \mathrm{~g}$ skim milk, $15 \mathrm{~g}$ agar, $500 \mathrm{~mL}$ saf su), lipolitik aktivitenin belirlenmesinde Tribütirin agar (TA) (5 g pepton, $3 \mathrm{~g}$ yest ekstarakt, $10 \mathrm{~mL}$ Tribütirin, $15 \mathrm{~g}$ agar ve $1000 \mathrm{~mL}$ saf su) ve amilaz enzim aktivitesinin belirlenmesinde ise Nişasta hidroliz agar (NA) (5 g beef ekstrakt, $20 \mathrm{~g}$ çözülebilir nişasta, $10 \mathrm{~g}$ triptoz, $5 \mathrm{~g} \mathrm{NaCl}, 15 \mathrm{~g}$ agar, $1 \mathrm{~L}$ saf su) kullanılmıştır. Sterilizasyondan sonra Petri kutularına dökülen besiyerlerinin üzerine $10 \mu \mathrm{L}$ aktif maya kültürlerini içeren $6 \mathrm{~mm}$ çaplı steril diskler yerleştirilmiş ve $30^{\circ} \mathrm{C}$ de 5 gün inkübasyona bırakılmıştır. Diskler etrafinda oluşan zonların çap1 dijital kumpas ile ölçülmüştür. Proteolitik ve lipolitik aktivite de oluşan zon çapları $\mathrm{d}<2 \mathrm{~mm}$ : Enzim aktivitesi düşük, $\mathrm{d}=2-10 \mathrm{~mm}$ : Enzim aktivitesi orta, $\mathrm{d}>10$ $\mathrm{mm}$ : Enzim aktivitesi yüksek olarak değerlendirilmiştir. Amilaz enzim aktivitesinde 
zonların daha berrak görünmesini sağlamak amaciyla besiyerine birkaç damla Gram iyot çözeltisi (\%0.5 iyot, $1 \mathrm{~g}$ potasyum iyodür, $\mathrm{pH}$ 7) ilave edilmiştir.

\section{Mayaların Üreyi Hidroliz Edebilme Yeteneği} YPD (Yeast Extract-Peptone-Dextrose) siv1 besiyerinde aktifleştirilen ve optik yoğunlukları spektrofotometre'de $600 \mathrm{~nm}$ de 0.6'ya ayarlan kültürlerin üre hidroliz etme yetenekleri Üre besiyerinde ( $20 \mathrm{~g}$ üre, $5 \mathrm{~g} \mathrm{NaCI}, 2 \mathrm{~g} \mathrm{KK_{2 }} \mathrm{PO}_{4}, 1 \mathrm{~g}$ pepton, $1 \mathrm{~g}$ glukoz, $12 \mathrm{~mL}$ fenol kırmızısı, $2 \mathrm{~g}$ $\mathrm{Na}_{2} \mathrm{HPO}_{4}, 100 \mathrm{~mL}$ saf su karıştırlarak pH 7'ye ayarlanmıştır) belirlenmiştir. Besiyeri renginin sarıdan pembeye dönüşmesi üreaz pozitif olarak yorumlanmıştır (Kim vd., 2004).

\section{Mayaların Farklı Tuz Konsantrasyonlarında ve Farklı Sicaklıklarda Canlılıkları}

Mayaların farklı tuz konsantrasyonlarında (\%4, $\% 6, \% 10 \mathrm{NaCl}$ ) (Abdel Nasser ve Moghaz, 2010) ve farklı sicaklıklarda $\left(30^{\circ} \mathrm{C}\right.$ ve $\left.37^{\circ} \mathrm{C}\right)$ (Barnett vd., 2000) canlı mikroorganizma saylları seri dilüsyonlar yapilarak $\log \mathrm{KOB} / \mathrm{mL}$ cinsinden hesaplanmıştır (Halkman, 2019).

\section{İstatistiksel Analizler}

Tüm çalışmalar, her çalışma için paralel sayısı değişmekle birlikte genel olarak üç paralelli ve iki tekerrürlü olacak şekilde yapılmışır. $\mathrm{Bu}$ çalışmalardan elde edilen veriler bu tekrarlann ortalaması \pm standart sapma (SD) şeklinde verilmiştir. Mikrobiyolojik çalışmalarda kullanılan istatistiksel analizlerde SPSS Inc. Software (22.0 Versiyonu; SPSS Inc., Chicago, IL) kullanılmıstır. Mayaların proteolitik ve lipolitik aktivitelerinin zon çapları arasında korelasyon olup olmadığ1 korelasyon testi ile analiz edilmiştir. Mayaların farklı tuz konsantrasyonlarında canlı hücre sayıları arasındaki farklılı̆̆ın anlamlı olup olmadığı LSD ve Tukey $(P<0.05)$ testleri ile analiz edilmiştir. 8 maya izolatının iki farklı sıcaklıkta canlı hücre sayıları arasındaki farklılı̆̆ı anlamlı olup olmadığı t-Testi $(P<0.05)$ ile analiz edilmiştir.

\section{SONUÇ VE TARTIŞMA}

Artan nüfus, kırsaldan kente göç ve sanayileşme gibi faktörler endüstriyel gıda üretimini kaçınılmaz kılmıştır. Endüstriyel ölçekte fermente gıda üretiminde kaliteyi her zaman aynı ölçüde koruyabilmek geleneksel yöntemlerle mümkün değildir. Bu amaçla, fermente gida üretiminde hem standartlaşmaya hem de kalite kontrolüne olanak tanıyan starter kültürlerin kullanılması bir zaruriyettir (Kieliszek vd., 2017).

Starter kültürlerin temel işlevleri arasında; asit oluşturma, proteoliz ve lipoliz, lezzet ve aroma bileşiklerinin oluşumunda rol alması ve zararlı bakterilerin inhibisyonu sayllabilir (Andrade vd., 2017). Mayaların starter aktivite özelliklerinden dolayı endüstride kullanımlarına önem verilmektedir (Andrade vd., 2017). Yapılan araştırmalara göre peynirlerden izole edilen maya türlerinin çeşitlilik gösterdiği görülmektedir. Buna rağmen aralarında Kluyveromyces marxianus, Debaryomyces hansenii, Saccharomyces cerevisiae, Yarrowia lipolytica, Trichosporon cutaneum (beigelii), Rhodotorula mucilaginosa, Torulaspora delbrueckii' nin bulunduğu 10 tür en sık rastlanılan mayalardır (Suzzi vd., 2001). Peynirlerde tuzlamayı takiben maya biyotasinda, Kluyveromyces lactis, K. marxianus ve T. delbrückii gibi laktoz pozitif mayalar hâkim olmaktadır. Olgunlaşma koşulları; özellikle de sıcaklık ve bağıl nem, peynirdeki maya biyotası kompozisyonunu önemli ölçüde etkilemektedir (Wyder, 2001). Asit üretimine dâhil olmayan ancak, olgunlaşma aşamasında yardımcı destek mikroorganizma olarak mayalar ( $K$. marxianus, $K$. lactis, D. hansenii, Geothricum candidum, Dipodascus capitatus, S. cerevisiae, S. unisporus, S. exiguns, Candida catenulata, C. intermedia) oldukça önemli bir role sahiptir (Oğuz ve Andiç, 2019).

Bazı mayaların yüksek lipolitik ve proteolitik aktiviteye sahip olmaları, aminoasit, yağ asitleri ve esterler gibi aroma oluşumuna öncülük eden maddelerin meydana gelmesinde büyük rol oynamaktadır (Azad ve Tomar, 2016). Önemli starter kültür özelliklerinden biri proteolitik aktivite olduğu için bu çalsşmada 8 Cryptococcus bumicola maya izolatının proteolitik aktiviteleri agar spot yöntemi ile belirlenmiştir. Mayaların proteolitik aktiviteleri sonucunda oluşturdukları en büyük şeffaf zon çap1 $C$. bumicola MBP7'de $(17.40 \mathrm{~mm})$ tespit edilirken, en küçük şeffaf zon çap1 C. bumicola MBP3'te $(10.27 \mathrm{~mm})$ belirlenmiştir (Çizelge 1). 
Çizelge 1. İzolatların proteolitik, lipolitik, amilaz enzim aktiviteleri ve üreyi hidroliz edebilme yetenekleri

Table 1. Proteolytic, lipolytic, amylase ensyme activities, and ability to bydrolyze urea of isolates

\begin{tabular}{|l|c|c|c|c|}
\hline İzolat & $\begin{array}{c}\text { Proteolitik } \\
\text { aktivite zon çap1 } \\
(\mathrm{mm})\end{array}$ & $\begin{array}{c}\text { Lipolitik aktivite } \\
\text { zon çap1 (mm) }\end{array}$ & $\begin{array}{c}\text { Amilaz enzim } \\
\text { aktivite zon çap1 } \\
(\mathrm{mm})\end{array}$ & $\begin{array}{c}\text { Üreyi hidroliz } \\
\text { edebilme } \\
\text { yetenekleri }\end{array}$ \\
\hline C. humicola MBP1 & $\begin{array}{c}\text { Proteolytic activity } \\
\text { zone diameter } \\
(\mathrm{mm})\end{array}$ & $\begin{array}{c}\text { Lipolytic activity } \\
\text { zone diameter }(\mathrm{mm})\end{array}$ & $\begin{array}{c}\text { Amylase ensyme } \\
\text { activity zone diameter } \\
(\mathrm{mm})\end{array}$ & $\begin{array}{c}\text { Ability to } \\
\text { bydrolyze urea }\end{array}$ \\
\hline C. humicola MBP2 & $13.22 \pm 0.32$ & $10.47 \pm 0.20$ & $14.54 \pm 1.88$ & $\begin{array}{c}\text { Zaylf } \\
\text { (Weak) }\end{array}$ \\
\hline C. humicola MBP3 & $10.23 \pm 0.01$ & $10.28 \pm 0.83$ & $13.09 \pm 0.68$ & $\begin{array}{c}\text { Yok } \\
\text { (No Ability) }\end{array}$ \\
\hline C. humicola MBP4 & $13.80 \pm 0.83$ & $9.96 \pm 0.32$ & $13.49 \pm 0.55$ & $\begin{array}{c}\text { Yok } \\
\text { (No Ability) }\end{array}$ \\
\hline C. humicola MBP5 & $12.90 \pm 0.45$ & $9.12 \pm 1.02$ & $10.96 \pm 0.64$ & $\begin{array}{c}\text { Zaylf } \\
\text { (Weak) }\end{array}$ \\
\hline C. humicola MBP6 & $11.86 \pm 0.20$ & $10.68 \pm 1.15$ & $8.87 \pm 0.19$ & $\begin{array}{c}\text { Zaylf } \\
\text { (Weak) }\end{array}$ \\
\hline C. humicola MBP7 & $17.40 \pm 0.08$ & $12.44 \pm 1.21$ & $12.78 \pm 1.09$ & $\begin{array}{c}\text { Güçlü } \\
\text { (Strong) }\end{array}$ \\
\hline C. humicola MBP8 & $11.98 \pm 0.16$ & $9.84 \pm 0.99$ & $12.42 \pm 0.51$ & $\begin{array}{c}\text { Zaylf } \\
\text { (Weak) }\end{array}$ \\
\hline
\end{tabular}

Mayaların peynir mikrobiyotasında önemli bir yere sahip olduğu, proteolitik ve lipolitik enzimleri, alkali ürünler üretimi ve peynir kitlesine penetrasyonları ile olgunlaşmada önemli bir rol üstlenmektedirler (Azad ve Tomar, 2016; Kieliszek vd., 2017).

Sütün yapisında bulunan lipaz enzimi ile starter kültür olarak kullanılan mayaların üretmiş oldukları ekstraselüler lipaz enzimleri vasitasılla, sütün temel bileşenlerinden olan trigliseritler, gliserol ve serbest yağ asitlerine hidroliz olmaktadır (Budak vd., 2016). Serbest yağ asitleri de peynirin tat ve aroma gelişimine yardımc1 olmaktadır. Bir çalışmada yardımcı starter kültür olarak kullanilan mayaların proteolitik ve lipolitik aktiviteleri sonucu peynirde tat ve koku oluşturduğu belirtilmiştir (Carrasco vd., 2016). Peynir olgunlaşması bakımından katkısı olabilecek mayaların lipolitik özellikler taşıması peynirin lezzeti açısından önemli olduğundan çalışmamızda, mayalanın lipolitik aktiviteleri mayaları içeren disklerin etrafında oluşan şeffaf zonlara göre tayin edilmiştir. Sekiz maya izolatnda en büyük zon çap1 $12.44 \mathrm{~mm}$ ile $C$. bumicola MBP7'da tespit edilirken, en küçük şeffaf zon çap $19.12 \mathrm{~mm}$ ile $C$. bumicola MBP5 mayasında bulunmuştur. Mayaların proteolitik ve lipolitik aktivite zon çapları arasında korelasyon olup olmadiğı Pearson Korelasyonuna göre tespit edilmiş ve bir korelasyon $(\mathrm{r}=0.661)$ olduğu tespit edilmiştir.

Feta peyniri salamurasindan izole edilen $S$. cerevisiae suşlarının $D$. hansenii suşlarından daha fazla lipolitik aktivite gösterdiği rapor edilmiştir. Her iki mikroorganizmanın da lipolitik özellikleri bakımından Feta peyniri olgunlaşmasına katkıda bulunabilecekleri savunulmuştur (Bintsis vd., 
2003). Guerzoni vd., (2001) çeşitli kaynaklardan izole edilen 12 Yarrowia lipolytica türünün lipolitik aktivite gösterdiklerini bildirmişlerdir.

Çalışmalarda elde edilen sonuçlar değerlendirildiğinde, farklı maya türlerinin farklı düzeylerde proteolitik ve lipolitik aktiviteye sahip olabilecekleri ve bununda peynirlerin olgunlaşmasında katkısı olabileceği şeklinde değerlendirilmiştir.

Mayalar üreyebilmek için azot kaynağına ihtiyaç duyarlar. Fermantasyon sirasinda arjinin aminoasidi yan ürün olarak üreyi oluşturur. Üre, azot kaynağı açısından zengindir ve mayalar için de önemli azot kaynağıdır. Çünkü mayaların gelişimi için azot kaynağının azalmaması gerekir (Wu vd., 2017). Üre, baz1 mikroorganizmalar tarafindan hidroliz edilerek amonyak ve karbamata dönüşür. Amonyak alkali madde olduğundan ortamın asitliğini azaltarak $\mathrm{pH}$ 'ın yükselmesi açısından önemlidir (Escribano vd., 2017). Araşturmada aktif maya kültürleri \%2 oranında üre içeren YEPD besiyerine inoküle edilmiştir. Besiyeri renginin sarıdan pembeye dönüşümü üre hidroliz yeteneği olarak değerlendirilmiştir. Yapılan bu çalışmada 8 maya izolatının üreyi hidroliz edebilme yeteneği araştırılmıs ve araştırmada kullanılan suşlardan $C$. bumicola MBP2, MBP3'ün üreyi hidroliz edebilme yeteneği yok iken, MBP1, MBP4, MBP5, MBP6, MBP8 izolatlarının üreyi hidroliz edebilme yeteneğinin zaylf olduğu, C. bumicola MBP7'nin ise üreyi hidroliz edebilme yeteneğinin güçlü olduğu tespit edilmiştir (Çizelge 1). Mayaların üreyi hidroliz etme yeteneği ile ilgili herhangi bir çalışmaya rastlanılmamıştır.

Tuza dirençli olarak canlılığını sürdüren mayalar peynir etrafinda mikrofilm tabakası oluştururlar ve peynirin ekosistem içerisinde gelişimlerini sağlayarak peynirin tat ve aromasına katkı sağlarlar (Asada vd., 2020). Bu çalışmada 8 maya izolatının farkl $\mathrm{NaCl}$ konsantrasyonlarında $(\% 0, \% 4, \% 6$, \%10) canlı hücre saylları tespit edilmiştir. Konsantrasyon artışına bağlı olarak canlılık miktarlarındaki değişimler Çizelge 2'de verilmiştir. Mayaların kontrol besiyerinde (YEPD) canl hücre sayllar1 $3.10 \log \mathrm{KOB} / \mathrm{mL}$ (MBP6) ile 2.71 $\log \mathrm{KOB} / \mathrm{mL}$ (MBP2) arasinda olduğu tespit edilmiştir. Farklı tuz konsantrasyonlarında mayaların canlı hücre sayıları arasında anlamlı bir farklılık tespit edilmiştir $(P>0.05)$ Mayaların en yüksek canlılık gösterdikleri tuz konsantrasyonu $\% 4$ iken, en düşük canlllık gösterdikleri tuz konsantrasyonu ise \%10'dur. Mayalar \%4'lük NaCl'lü YEPD besiyerinde (MBP4 ve MBP6 izolatları hariç kontrol besiyerinde daha iyi gelişme göstermişlerdir) daha iyi gelişme gösterdikleri tespit edilmiştir.

Hücredeki neredeyse tüm biyokimyasal süreçleri etkileyen termodinamik parametrelerden biri sıcakliktır. $\mathrm{Bu}$ parametre canlı hücrelerin ölçülmesi için araştırma gruplanı tarafindan kabul edilmiştir. Sicaklığı ayarlanmasi, mikroorganizmaların çoğalmasını engellemek için yaygın olarak kullanılmaktadır (Liu vd., 2017). Mayalar için sıcaklık, beslenme ve gelişme açısından oldukça önemlidir. Sıcaklık enzim aktivitesini etkileyen en önemli faktörlerden biridir. Sicaklıkta meydana gelecek değişiklik oluşan metabolizma ürünlerinide etkilemektedir (Molon ve Zadrag-Tecza, 2016). Bu çalışmada C. bumicola türüne ait 8 maya kültürünün $30^{\circ} \mathrm{C}$ ve $37^{\circ} \mathrm{C}$ de canlı hücre sayıları Çizelge $2^{\prime}$ de verilmiştir. $C$. humicola türüne ait 8 izolatın hepsi her iki sıcaklık derecesinde de farklı miktarlarda canlilık gösterirken, izolatlar içinde $C$. bumicola MBP4 izolatının $30^{\circ} \mathrm{C}$ 'de en yüksek canlılı̆g (3.95 $\log \mathrm{KOB} / \mathrm{mL}$ ) sahip olduğu görülmektedir. MBP4 ve MBP6 izolatları hariç diğer izolatların $37^{\circ} \mathrm{C}$ 'de daha iyi gelişme gösterdikleri tespit edilmiştir. Mayaların her iki sıcaklıktaki canlı hücre sayıları arasındaki farklılığın $(P=0.00)$ anlamlı olduğu belirlenmiştir.

Mayaların soğuğa adaptasyonu, mevcut karbon kaynaklarını kullanmak için hücre dışı hidrolitik enzimlerin üretilmesi ile mümkün olmaktadır ve bu yolla besin geri dönüşümü ve organik madde mineralizasyonuna katkıda bulunmaktadırlar (Baeza vd., 2017). Amilazlar, g1da, deterjan, çamaşırhane, tekstil, unlu mamuller ve biyoyakıtlar gibi endüstrilerde kullanım için büyük potansiyele sahiptir. Özellikle gida sektöründe amilaz enzim aktivitesine sahip mikroorganizmaların belirlenmesi çok önemlidir. 
Mayalarda bu alanda uygun adaylar olarak görülmektedirler. Mayaların amilaz enzim aktivitesi, mayanın fermantasyon için ihtiyaç duyduğu şekerin oluşmasını, ekmek oluşmasını sağlayan mayalarda hamurun kivamlı olmasını sağlamaktadır (Carrasco vd., 2016; Selwal vd., 2017). Bu çalışmada, mayaların amilaz enzim aktivitesi araştırılmasında agar spot yönetimi kullanılarak mayalarin steril disk etrafinda oluşturduğu berrak zon çap1 ölçülmüştür ve Çizelge 1'de verilmiştir. Yüksek amilaz aktivitesi sahip olan izolatlar olarak C. humicola MBP1 (14.535 mm), C. bumicola MBP4 (13.49 mm), C. bumicola MBP3 $(13.09 \mathrm{~mm})$ ve $C$. bumicola MBP7 $(12.78 \mathrm{~mm})$ tespit edilmiştir.

Çizelge 2. İzolatların farklı tuz konsantrasyonunda ve farklı sıcaklıklarda canlı hücre sayısı (log $\mathrm{KOB} / \mathrm{mL})$

Table 2. The number of live cells of the isolates at different salt concentrations and temperatures (log CFU/mL)

\begin{tabular}{|c|c|c|c|c|c|c|}
\hline \multirow{3}{*}{$\begin{array}{l}\text { İzolatlar } \\
\text { Isolates }\end{array}$} & \multicolumn{4}{|c|}{$\begin{array}{l}\text { Canlı hücre say1s1 }(\log \mathrm{KOB} / \mathrm{mL}) \\
\text { Live cell count }(\log C F U / m L)\end{array}$} & \multicolumn{2}{|c|}{$\begin{array}{c}\text { Canlı hücre sayis1 (log } \\
\mathrm{KOB} / \mathrm{mL}) \\
\text { Live cell count }(\log C F U / m \mathrm{~L})\end{array}$} \\
\hline & \multicolumn{4}{|c|}{$\begin{array}{l}\text { Tuz } \\
\text { Salt }\end{array}$} & \multicolumn{2}{|c|}{$\begin{array}{c}\text { Sicaklik } \\
\text { Temperature }\end{array}$} \\
\hline & $\begin{array}{l}\text { Kontrol } \\
\text { (YPD) } \\
\text { Control }\end{array}$ & $\% 4 \mathrm{NaCl}$ & $\% 6 \mathrm{NaCl}$ & $\% 10 \mathrm{NaCl}$ & $\begin{array}{c}37^{\circ} \mathrm{C} \\
\text { (Kontrol) } \\
\text { (Control) }\end{array}$ & $30^{\circ} \mathrm{C}$ \\
\hline MBP1 & $2.88 \pm 0.40$ & $3.09 \pm 1.08$ & $2.88 \pm 0.07$ & $2.69 \pm 0.53$ & $3.31 \pm 0.03$ & $3.24 \pm 0.03$ \\
\hline MBP2 & $2.71 \pm 0.70$ & $3.26 \pm 1.80$ & $2.91 \pm 0.76$ & $2.59 \pm 0.07$ & $3.20 \pm 0.21$ & $2.97 \pm 0.53$ \\
\hline MBP3 & $3.04 \pm 0.40$ & $3.17 \pm 0.73$ & $2.82 \pm 0.83$ & $2.50 \pm 0.21$ & $3.25 \pm 0.95$ & $3.23 \pm 0.07$ \\
\hline MBP4 & $2.89 \pm 1.00$ & $2.77 \pm 0.33$ & $2.73 \pm 0.40$ & $2.63 \pm 1.55$ & $3.32 \pm 0.70$ & $3.95 \pm 0.47$ \\
\hline MBP5 & $2.87 \pm 0.66$ & $3.18 \pm 0.61$ & $2.81 \pm 1.14$ & $2.62 \pm 0.98$ & $3.27 \pm 0.61$ & $3.20 \pm 0.73$ \\
\hline MBP6 & $3.10 \pm 0.10$ & $3.00 \pm 0.40$ & $2.98 \pm 0.66$ & $2.64 \pm 0.53$ & $3.20 \pm 0.09$ & $3.26 \pm 01.21$ \\
\hline MBP7 & $2.87 \pm 0.66$ & $2.89 \pm 0.48$ & $3.14 \pm 1.47$ & $2.66 \pm 1.90$ & $3.33 \pm 0.60$ & $2.82 \pm 0.66$ \\
\hline MBP8 & $3.06 \pm 0.33$ & $3.07 \pm 1.8$ & $2.51 \pm 1.21$ & $2.60 \pm 0.03$ & $3.17 \pm 0.07$ & $3.04 \pm 0.87$ \\
\hline
\end{tabular}

Yapılan literatür taramalarnnda C. bumicola türünde proteolitik aktivite, lipolitik aktivite, üreyi hidroliz etme yeteneği, farklı tuz konsantrasyonlarında ve sıcaklık derecelerinde canllık miktarları ve amilaz enzim aktivitesi ile ilgili herhangi bir literatür bilgisine rastlanılmamışır ve bu maya türünün ülkemizde de dâhil olmak üzere starter kültür olarak kullanımına yönelik araştırma yapilmamıştır. Cryptococcus cinsinin bilinen ve tanımlanmış 34 türü vardır ve hemen hemen hepsi (C. neoformans, C. albidus, C. laurentii ve C. curvatus gibi) klinik olarak izole edilmiştir (Fell ve StatzellTallman, 1998). Çalışmamızda Beyaz peynirden $C$. bumicola'nın izole edilmesinin nedeninin ya süt kaynağından peynirin olgunlaşması aşamasına kadar geçen süre içerisindeki bulaştan dolayı ya da çevresel etkilere bağlı olarak bulaşması ile izole edilmiş olabileceğini düşünmekteyiz. Ülkemizdeki süt sağımı koşulları ve peynir üretimindeki kontaminasyonlar göz önüne alındığında $C$. bumicola’nın varlığının normal olduğunu düşündürmüştür.

\section{ÇIKAR ÇATIŞMASI BEYANI}

Yazarlar arasında çlkar bulunmamaktadır.

\section{YAZAR KATKILARI}

YB ve $Z Y$ araştırmayı tasarladı. SA ve DU analizleri gerçekleştirdi. DU, ZY ve AS makaleyi yazdı. HİK ve ÖŞ makalenin son halini okudu ve onayladi. 


\section{KAYNAKLAR}

Abdel Nasser, A., El- Moghaz, (2010). Comprative study of salt tolerance in Saccharomyces cerevisiae and Pichia pastoris yeast strains. Adv Biol, 1(1):169-176.

Andrade, R. P., Melo, C. N., Genisheva, Z., Schwan, R. F. and Duarte, W. F. (2017). Yeasts from Canastra cheese production process: Isolation and evaluation of their potential for cheese whey fermentation. Food Res Int, 91, 72-79.

Asada, C., Sasaki, C., Oka, C. (2020). Ethanol production from sugarcane bagasse using pressurized microwave treatment with inorganic salts and salt-tolerant yeast. Waste Biomass Valor, 11, 2001-2007.

Azad, K., Tomar, R. (2016). Partial purification of histone $\mathrm{H} 3$ proteolytic activity from the budding yeast Saccharomyces cerevisiae. Yeast, 33 (6), 217-226.

Baeza M., Alcaíno J., Cifuentes V., Turchetti B., Buzzini P. (2017). Cold-active enzymes from cold-adapted yeasts. Biotechnol Yeasts Filament Fungi, 48 (6), 297-324.

Barnett, J., A. Payne, R.W. and Yarrow, D. (2000). Yeasts: Characteristics and identification, ( $3^{\text {rd }} \mathrm{ed}$.), Cambridge, United Kingdom. Cambridge University Press.

Bintsis, T. and Robinson, R. K. (2004). A study of the adjunct cultures on the aroma compounds of Feta-type cheese. Food Chem, 88(3), 435-441.

Budak, S.., Wiebenga, A., Bron, P., Vries, R. (2016). Protease and lipase activities of fungal and bacterial strains derived from an artisanal raw ewe's milk cheese. Int J Food Microbiol, 237 (21), 1727.

Carrasco, M., Villarreal, P., Barahona, S., Alcaíno, J., Cifuentes, V., Baeza, M. (2016). Screening and characterization of amylase and cellulase activities in psychrotolerant yeasts. BMC Microbiol, 16 (21), 1-9.

Cotter, P.D., Beresford, T.P. (2017). Microbiome Changes During Ripening. In: Cheese: Chemistry, Physics and Microbiology (4th Edition), McSweeney, P., Fox, P., Cotter, P. Everett, D. (Eds.), Volume 1, Academic Press, the UK, pp. 389-409.
Darsanaki, R.K., Aliabadi, M.A. and Chakoosari, M.M.D., (2013). Antibiotic resistance of lactic acid bacteria. Sci J Microbiol, 2(11), 201-206.

De Vuyst L, Harth H, Van Kerrebroeck S, Leroy F. (2016). Yeast diversity of sourdoughs and associated metabolic properties and functionalities. Int J Food Microbiol 239, 26-34.

Demirgül, F., Tuncer, Y. (2017). Detection of antibiotic resistance and resistance genes in Enterococci isolated from Sucuk, a traditional Turkish dry-fermented sausage. Korean J Food Sci Anim Resour, 37(5), 670-681.

Eroğlu, E., Özcan, T. (2018). Sütün enzimatik koagülasyonu ve peynir üretiminde bitkisel prhtılaştırıcilar. Bursa Uludag Üniv. Ziraat Fak. Derg., 32(2), 201-214.

Escribano, R., González-Arenzana, L., Garijo, P., Berlanas, C., López-Alfaro, I., López, R., Gutiérrez, A.R., Santamaría, P. (2017). Screening of enzymatic activities within different enological non-Saccharomyces yeasts. J Food Sci Technol 54, 1555-1564.

Fell, J.W., Statzell-Tallman A. (1998). Cryptococcus V In: Kurtzman C.P. and Fell J.W. (eds), The Yeasts-a Taxonomic Study. 4th edn. Elsevier, Amsterdam, The Netherlands, pp. 742-767..

Ferreira, A.D., Viljoen B.C. (2003). Yeasts as adjunct starters inmatured Cheddar cheese, Int J Food Microbiol, 86(1-2), 131-140.

Fröhlich-Wyder, M. T., Arias-Roth, E., Jakob, E. (2019). Cheese Yeasts. Yeasts, 36(3): 129-141. Doi: 10.1002/yea.3368.

Guerzoni, M.E., Gobbetti, M., Lanciotti, R., Vannini, L. and Chaves, L.C. (2001).Yarrowia lipolytica as potential ripening agent inmilk products, Yeasts in The Dairy Industry: Positive and Negative Aspects, Proceedings of International Dairy Federation Symposium, Copenhagen, 23-33.

Gürsoy, A., Türkmen, N. (2018). Adjunct Cultures in Cheese Technology. In: Microbial Cultures and Ensymes in Dairy Technology, IGI Global, Hershey PA, the USA, pp. 234-256.

Halkman, A.K. 2019. 08. Sayım Yöntemleri. Gıda Mikrobiyolojisi. Editör: A. Kadir Halkman. Başak 
Matbaacilik ve Tanıtım Hizmetleri Ltd, Ankara, 648 s. ISBN: 978-605-245-683-5

Irlinger, F., Helinck, S., Jany, J. L. (2017). Secondary and Adjunct Cultures. In: Cheese: Chemistry, Physics and Microbiology (4th Edition), McSweeney, P., Fox, P., Cotter, P. Everett, D. (Eds.), Volume 1, Academic Press, the UK, pp. 273-300.

Kara, R., Akkaya, L. (2015). Afyon tulum peynirinin mikrobiyolojik ve fiziko-kimyasal özellikleri ile laktik asit bakteri dağılımlarının belirlenmesi. Aku J. Sci. Eng, 15: 1-6. Doi: 10.5578/fmbd.8717.

Karaman, K., Sagdic, O., Durak, M.Z. (2018). Use of phytase active yeasts and lactic acid bacteria isolated from sourdough in the production of whole wheat bread. Food Sci Technol, 91, 557-567.

Kieliszek, M., Kot, A., Bzducha-Wróbel, A., BŁażejak, S., Gientka, I., Kurcz, A. (2017). Biotechnological use of Candida yeasts in the food industry: A review. Fungal Biol Rev, 31 (4), 185198.

Selwal, K.K., Li, Y.F., Yu, Z. (2017) Functional display of amylase on yeast surface from Rhizopus oryzae as a novel enzyme delivery method. Food Biotechnol, 31(4), 233-244.

Ksonzeková P, Bystrickyb P, Vlckováb S, Pätoprst'yb, V, Pulzováa L, Mudro nováa D, Kubaskováa T, Csanka T, L. (2016). Exopolysaccharides of Lactobacillus reuteri: Their influence on adherence of E. coli to epithelial cells and inflammatory response. Carbohydr Polym, 141: 10-19.

Liu, J., Li, L., Zhou, L., Li, B., Xu, Z. (2017). Effect of ultrasound treatment conditions on Saccharomyces cerevisiae by response surface methodology. Microb Pathog, 111,497-502.

Molon, M. and Zadrag-Tecza, R. (2016). Effect of temperature on replicative aging of the budding yeast Saccharomyces cerevisiae. Biogerontology, 17(2), 347-357.

Oğuz, Ş, Andiç, S. (2019). Peynir Üretiminde Kullanılan Starter Kültürler. Gıda, 44 (6), 11741196.
Picon, A. (2018). Cheese Microbial Ecology and Safety. In: Global Cheesemaking Technology: Cheese Quality and Characteristics, Papademas, P., Bintsis, T. (Eds.), John Wiley \& Sons Ltd, West Sussex, UK, pp. 71-99.

Piotr, J., Maria, W., Barbara, A., Jozafe, C., Adam, M. (2005). Diversity of physiological and biochemicial properties within yeast species occurring in rpkpol cheese. Pol. J. Food Nutr. Sci. 3:257-261.

Wu, Q., Lin, J., Cui, K., Du, R., Zhu, Y., Xu, Y. (2017). Effect of microbial interaction on urea metabolism in Chinese liquor fermentation. $J$ Agric Food Chem, 65(50), 11133-11139.

Rossouw, D., Bauer, FF. (2016). Exploring the phenotypic space of non-Saccharomyces wine yeast biodiversity. Food Microbiol, 55:32-46.

Russo, P., Fares, C., Longo, A., Spano, G., Capozzi, V. (2017). Lactobacillus plantarum with broad antifungal activity as a protective starter culture for bread production. Food, 6 (12), 110.

Soran, G. Ş., Çelik, Ş. (2018). Telemesi haşlanan geleneksel peynirlerimizin üretimine uygun doğal starter kültür geliştirilmesi. HU. Müh. Derg., 3(1), 15-19.

Kim, S., Kim, H., Chae, H. (2004). Selection of probiotic yeasts from soil, characterization and application for feed additives. Agric. Chem Biotechnol. 47(1), 20-26.

Suzzi, G., Lanorte, M.T., Galagno, F., Andrighetto, C., Lombardi, A., Lanciotti, R., Guerzoni, M.E., (2001). Proteolytic, lipolytic, and molecular characterization of Yarrowia lipolytica 1solated from cheese, Int J Food Microbiol, 69,69-77.

Tekinşen, O.C. (2000). Süt Ürünleri Teknolojisi. Selçuk Üniv Basımevi, Konya.

Wyder, M.T. (2001). Yeasts in Dairy Products, Swiss Federal Dairy Research Station, Fam Info No: 425, Liebefeld, CH-3003 Berne. 